\title{
Chickpea Seeds Ferritin as a Potential Source in the Treatment of Iron Deficiency Anemia
}

\author{
Yun Huang ${ }^{1,3, *}$, Min Xin ${ }^{1}$, Qian Li ${ }^{1}$, Xiaohong Luo ${ }^{3}$, Xiaowen Wang ${ }^{2}$, Xianwei Zou ${ }^{1}$, Xuan Liu ${ }^{1}$, Benke Chen ${ }^{3}$, \\ Jintian Tang ${ }^{1}$ \\ ${ }^{1}$ Institute of Medical Physics and Engineering, Department of Engineering Physics, Tsinghua University, Beijing, China \\ ${ }^{2}$ Institute of neurological disorders, Yuquan hospital, Tsinghua University, Beijing, China \\ ${ }^{3}$ Beijing Longcredit Essence Biotechnology Co. Ltd, Beijing, China \\ *Corresponding author: huangyun6626@hotmail.com
}

Received July 14, 2014; Revised October 28, 2014; Accepted November 05, 2014

\begin{abstract}
Iron deficiency anemia (IDA) is one of the most common nutritional problems that encountered all over the world. This study focused on the effects of chickpea seeds ferritin (CSF) as aniron supplement on IDA in rats. Six groups of female Wistar rats $(\mathrm{n}=8)$ were used, which contain (1) control group; (2) IDA model group; (3) $\mathrm{FeSO}_{4}$ positive control group (dosages of iron is $3 \mathrm{mg} /(\mathrm{kg} \bullet \mathrm{d}$ )); (4) CSF high-dose group (dosage of iron is 3 $\mathrm{mg} /(\mathrm{kg} \bullet \mathrm{d})$; (5) CSF medium-dose group (dosage of iron is $1.5 \mathrm{mg} /(\mathrm{kg} \bullet \mathrm{d})$ ); and (6) CSF low-dose group (dosage of iron is $0.75 \mathrm{mg} /(\mathrm{kg} \bullet \mathrm{d}))$. After 2 weeks, the hemoglobin $(\mathrm{Hb})$ concentration value, serum iron (SI) stores, body weights, blood parameters and tissue weights of anemic rats were measured, respectively. It showed that the $\mathrm{Hb}$ concentration value and SI stores were significantly increased in the iron supplement groups (CSF, $\left.\mathrm{FeSO}_{4}\right)$ compared with the IDA model group $(P<0.05)$. Additionally, the changes of red blood cell (RBC) number and HCT (Hematocrit) level in CSF groups were significantly greater than the IDA model group at the end of the experiment. All in all, compared with $\mathrm{FeSO}_{4}$ group, a higher bioavailability of iron and fewer side effects were observed in the CSF groups. Thus, the present study indicated that CSF was an effective source of iron supplement for the IDA model rats and could be developed as a functional product to overcome the malnutrition-related iron deficiency.
\end{abstract}

Keywords: iron deficiency anemia, chickpea seeds ferritin, hemoglobin, serum iron, iron supplement

Cite This Article: Yun Huang, Min Xin, Qian Li, Xiaohong Luo, Xiaowen Wang, Xianwei Zou, Xuan Liu, Benke Chen, and Jintian Tang, "Chickpea Seeds Ferritin as a Potential Source in the Treatment of Iron Deficiency Anemia." Journal of Food and Nutrition Research, vol. 2, no. 12 (2014): 876-879. doi: 10.12691/jfnr2-12-3.

\section{Introduction}

Iron-deficiency anemia (IDA) is one of the most prevalent nutritional problem in the world [1], and caused primarily due to the low content of dietary iron and inadequate intake of bioavailableiron. Pregnant women and children are the most likely to suffer from IDA, especially in the developing country. In recent years, IDA have resulted in a wide series of adverse outcomes including mental retardation [2,3], poor pregnancy outcomes [4], decreased immune function [5], bad work performance [6] and so on. Therefore, a good source of this microelement with a better bioavailability profile is required, and how to promote iron absorption seems to be a practical and effective means of combating and preventing iron deficiency anemia.

Currently, the treatment of IDA mainly constitutes supplementation with luminal iron present as $\mathrm{Fe}^{3+}$ and $\mathrm{Fe}^{2+}$ or dietary diversification. However, it is a pity that both forms of ions can form complexes with phytate, tannin, etc., preventing uptake into mucosal cells $[7,8,9,10]$; Moreover, it also can cause many side effects such as heartburn, abdominal pain, nausea, and diarrhea, all of which limit the general applicability of this kind of clinical application. Thus, food fortification seems to be the ideal strategy for prevention of this nutritional disorder in the world [11]. One of the methods being considered for fortification of the human diet with iron is food enrichment in plant ferritin, whose side effects and toxicity are relatively minimal [12]. Chickpea seeds ferritin appropriately provides an effective means of controlling the iron deficiency due to a high iron content with better absorption, so it is supposed to be explored a safe and efficient functional source for iron supplement.

Up to date, only few works have been done to deal with the existing association between iron deficiency and chickpea seeds ferritin, this work aimed to evaluate the effect of iron supplementation resulting from chickpea in rats with IDA. Crude phytoferritin was extracted from chickpea seeds, and particular emphasis of this study is placed on an attempt to lessen adverse effects, thereby providing an alternate iron supplement approach.

\section{Materials and Methods}




\subsection{Reagents and Materials Used}

Sodium hydrosulfite (West Long Chemical Co., Ltd, China); 1,10-Phenanthroline monohydrate (Tianjin Fucheng Chemical Reagent factory, China); Van Kampen Zijlstra (Rongbo Biological Technology Co., Ltd, China); $\mathrm{FeSO}_{4}$ (Sigma Company, American); EDTA-Na (Beijing Hundred LingKe Biological Technology Co., Ltd, China); Iron deficiency fodder (purchased from Keaoxieli fodder Co., Ltd, China)containing $5 \mathrm{mg}$ iron $\mathrm{kg}^{-1}$ diet. All other reagents used were of analytical grade or purer.

\subsection{Preparation of the Chickpea Seeds Ferritin (CSF)}

Dried chickpea seeds were obtained from the local market, and ferritin isolates were prepared and purified as following described method [13]: chickpea seeds soaked in deionized water at $4^{\circ} \mathrm{C}$ chromatography cabinet for about $15 \mathrm{~h}$. After filtration, the test samples were immersed with $\mathrm{KH}_{2} \mathrm{PO}_{4}-\mathrm{NaOH}$ buffer $(\mathrm{pH}=8.0)$ at the ratio of $1: 4(\mathrm{~g} / \mathrm{mL})$ for 2 hours, crude ferritin isolation via the salting out method with $70 \mathrm{mmol} / \mathrm{L} \mathrm{MgCl}_{2}$ was then obtained by using water washing twice after high-speed centrifugation. Resulting samples were finally lyophilized, powdered, and frozen at $-80^{\circ} \mathrm{C}$ until used.

\subsection{Experimental Animals}

The experiment performed for analysis of the availability of ferritin was conducted on groups of rats either with induced iron-deficiency anemia or non irondeficient. In the present study, forty-eight healthy female Wistarrats with a balanced initial body weight of $80 \pm 5 \mathrm{~g}$ were provided by animals laboratory of Tsinghua University. The rats were measured at appropriate conditions (a temperature of $25 \pm 1^{\circ} \mathrm{C}$, relative air humidity at the level of $55 \pm 5 \%$, and optimum daily lighting cycle, i.e. $12 \mathrm{~h}$ of light/12 h of darkness), and distilled deionized water was given continuously. All experimental procedures involving animals received the approval from the Animal Care and Use Committee of Tsinghua University.

After adaptation for 3 days, the rats were randomly divided into the control group and the IDA model groups. Eight rats were selected randomly and given normal diets as the control group. The remaining was given low iron diets for 4 weeks to generate an IDA animal model. The whole experimental process was strictly controlled to avoid iron stain. Hb levels were tested weekly, and IDA was defined as $\mathrm{Hb}$ values lower than $90 \mathrm{~g} / \mathrm{L}$.

Forty IDA rats were randomly assigned into 5 groups of eight animals, each with equal mean $\mathrm{Hb}$ values: the IDA model group; the positive group $\left(\mathrm{FeSO}_{4}\right.$, dosage of ironis $3 \mathrm{mg} /(\mathrm{kg} \cdot \mathrm{d}))$; the high-dose group(CSF, dosage of ironis 3 $\mathrm{mg} /(\mathrm{kg} \cdot \mathrm{d})$ ); the medium-dose group(CSF, dosage of ironis $1.5 \mathrm{mg} /(\mathrm{kg} \cdot \mathrm{d})$ ); the low-dose group(CSF, dosage of ironis $0.75 \mathrm{mg} /(\mathrm{kg} \cdot \mathrm{d}))$. Rats in the positive group were administered $\mathrm{FeSO}_{4}$ solution, rats in the CSF groups were administered the CSF suspension, while rats in the control and model group were administered distilled deionized water. All supplements were freshly prepared every day and intragastric administration was performed once at 10:00 AM each day for 2 weeks.

\subsection{Tissue and Blood Collection}

After overnight food deprivation, rats were first anesthetized with barbital sodium and blood samples were collected from the abdominal aorta into anticoagulant blood vessels for immediate $\mathrm{Hb}$ analysis and into centrifuge tubes for separation of the serum for future analyses. The rats were killed by decapitation, and the organs such as heart, liver, spleen and kidneys were removed, weighed and rapidly frozen in liquid nitrogen at$80^{\circ} \mathrm{C}$ for upcoming applications. The serum was separated by centrifugation at $3000 \mathrm{~g}$ for $5 \mathrm{~min}$ and stored at- $20^{\circ} \mathrm{C}$ for the following research.

\subsection{Statistical Analysis}

Statistical analyses were performed by SPSS 17.0 software for Windows (SPSS Inc., Chicago, IL, USA). The differences between the groups among treatments in each group were determined by one-way analysis of variances ANOVA. Comparisons of the means with $P<0.05$ were considered significantly different. Duncan's multiple-range tests were performed, and data were presented as means with their standard deviations.

\section{Results}

\subsection{Hb concentration, RBC Numbers and HCT Levels of Rats}

Table 1. The Hb concentration, RBC number and HCT level of rats in each group $(\bar{X} \pm \mathrm{s}, \mathbf{n}=\mathbf{8})$

\begin{tabular}{|c|c|c|c|c|c|c|}
\hline \multirow[t]{2}{*}{ Groups } & \multicolumn{2}{|c|}{ concentration of $\mathrm{Hb}(\mathrm{g} / \mathrm{L})$} & \multicolumn{2}{|c|}{$\mathrm{RBC}\left(10^{12} / \mathrm{L}\right)$} & \multicolumn{2}{|c|}{ HCT(\%) } \\
\hline & $\begin{array}{l}\text { after depletion } \\
\text { (4 weeks) }\end{array}$ & $\begin{array}{l}\text { after repletion } \\
\text { (2 weeks) }\end{array}$ & $\begin{array}{l}\text { after depletion } \\
\text { (4 weeks) }\end{array}$ & $\begin{array}{l}\text { after repletion } \\
\text { (2 weeks) }\end{array}$ & $\begin{array}{l}\text { after depletion } \\
\text { (4 weeks) }\end{array}$ & $\begin{array}{l}\text { after repletion } \\
\text { ( } 2 \text { weeks) }\end{array}$ \\
\hline Control & $113.3 \pm 9.9$ & $116.1 \pm 7.4$ & $7.9 \pm 0.7$ & $6.8 \pm 0.8$ & $43.9 \pm 4.1$ & $38.5 \pm 2.9$ \\
\hline Model & $87.1 \pm 7.8^{*}$ & $90.1 \pm 8.9 *$ & $6.5 \pm 0.4^{*}$ & $6.9 \pm 0.2$ & $38.6 \pm 1.6^{*}$ & $38.4 \pm 0.4$ \\
\hline $\mathrm{FeSO}_{4}$ & $89.7 \pm 6.4^{*}$ & $113.3 \pm 8.6$ & $6.8 \pm 0.7^{*}$ & $6.8 \pm 0.3$ & $39.3 \pm 2.6^{*}$ & $39.9 \pm 1.7$ \\
\hline Low-dose CSF & $86.4 \pm 8.1^{*}$ & $115.8 \pm 6.4$ & $6.8 \pm 0.9^{*}$ & $6.6 \pm 0.2$ & $40.9 \pm 1.8^{*}$ & $37.7 \pm 1.8$ \\
\hline Medium-dose CSF & $87.5 \pm 5.8^{*}$ & $114.8 \pm 5.3$ & $6.5 \pm 0.3^{*}$ & $6.9 \pm 0.6$ & $39.8 \pm 2.7^{*}$ & $38.8 \pm 2.3$ \\
\hline High-dose CSF & $87.1 \pm 7.9 *$ & $112.1 \pm 3.3$ & $6.7 \pm 0.8^{*}$ & $7.3 \pm 0.6^{*}$ & $38.5 \pm 2.1^{*}$ & $41.6 \pm 1.9^{*}$ \\
\hline
\end{tabular}

* compared with control group, $P<0.05$

The Hbconcentration, RBC numbers and HCT level in the experiment groups and the control group were not significantly different at the beginning of the experiment $(P>0.05)$ (Table 1$)$. However, the Hb, RBC and HCT levels in the iron-deficient diet groups were markedly lower than the control group after 4 weeks depletion $(P<$
0.05), suggesting that the proposed scheme was of great success. When the IDA rats were fed with iron supplements $\left(\mathrm{FeSO}_{4}\right.$ and $\left.\mathrm{CSF}\right)$ for 2 weeks, the Hbconcentrations were gradually recovered to the same level as the control group, and much higher than those of the model. These results suggested that CSF has the same 
therapy effects in supplementing iron as the $\mathrm{FeSO}_{4}$. In addition, RBC and HCT parameters displayed that the CSF high-dose group can even approached the higher level than the control group at the 6th weeks, while the $\mathrm{FeSO}_{4}$ group showed the nearly the same as the model.

\subsection{Serum Iron of Rats}

The recovery from IDA was also determined by measuring the concentration of serum iron (Table 2). The results showed that at the 4th week, the concentration of test groups have significantly differences from that of the control group $(P<0.05$, Table 3$)$. At the end of the experiment, the iron concentrations of the serum in the different dosages of CSF groups and the $\mathrm{FeSO}_{4}$ group were almost 1.3 fold higher than those of model group $(2.3 \pm 1.9 \mathrm{mg} / \mathrm{L})$, which was found to be statistically significant $(P<0.05)$, and slightly above the control group.

This result indicated that the samples were effective in the iron recovery.

Table 2. The serum iron concentration of rats in each group ( $\bar{X} \pm$ s, $\mathbf{n = 8 )}$

\begin{tabular}{ccc}
\hline & \multicolumn{2}{c}{ Serum iron(mg/L) } \\
\cline { 2 - 3 } Groups & $\begin{array}{c}\text { after depletion } \\
(4 \text { weeks })\end{array}$ & $\begin{array}{c}\text { afterrepletion } \\
(2 \text { weeks })\end{array}$ \\
\hline Control & $3.8 \pm 0.7$ & $4.3 \pm 0.9^{\Delta}$ \\
Model & $3.1 \pm 0.8^{*}$ & $2.3 \pm 1.9^{*}$ \\
FeSO $_{4}$ & $3.3 \pm 1.7^{*}$ & $5.4 \pm 1.6^{* \Delta}$ \\
Low-dose CSF & $3.2 \pm 0.6^{*}$ & $5.3 \pm 1.3^{*_{\Delta}}$ \\
Medium-dose CSF & $3.3 \pm 1.4^{*}$ & $5.5 \pm 1.1^{{ }^{*} \Delta}$ \\
High-dose CSF & $3.2 \pm 1.1^{*}$ & $5.3 \pm 1.6^{* \Delta}$ \\
\hline${ }^{*}$ Compared with control group, $P<0.05 ;{ }^{\circ}$ Compared with model group,
\end{tabular}
$P<0.05$

\subsection{Tissue Weight of Rats}

Table 3. The organ indices of rats ineach group $(\bar{X} \pm \mathbf{s}, \mathbf{n}=\mathbf{8})$

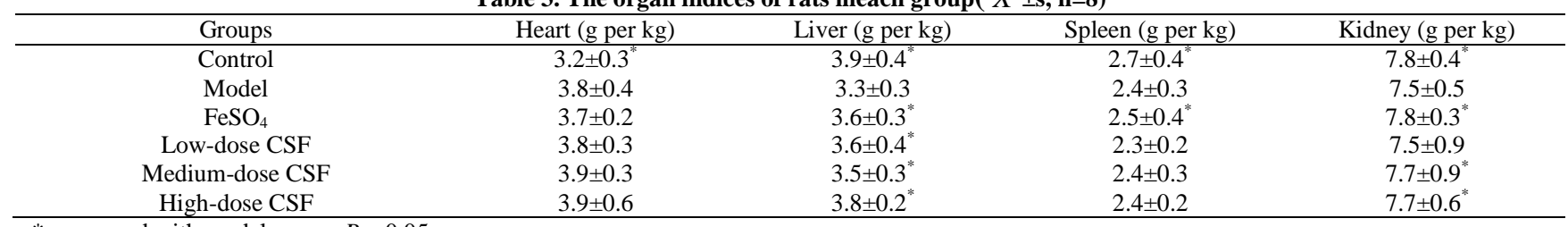

* compared with model group, $P<0.05$

Table 3 shows the relative tissue (heart, liver, spleen and kidney) weights in each group. The relative weights of the liver in the different dose groups have markedly improved compared with the model group. A similar result was observed in rats kidney treated with medium and high-dose CSF. However, no statistical differences were observed in their heart and spleen indices. These results further demonstrated that liver and kidney are the main storage site for iron, and both $\mathrm{FeSO}_{4}$ and CSF were effective iron supplements for IDA rats.

\subsection{Body Weight Gain of Rats}

The body weight changes of the rats are shown in Table 4. Initially, the mean body weight of the rats in the experiment groups and the control group did not differ $(P>0.05)$. After 4 weeks of low iron dietary treatment, the mean body weight in the model group was significantly lower than the control group $(P<0.05)$. When 5th and 6th weeks repletion, the mean body weight of the CSF and $\mathrm{FeSO}_{4}$ groups still lower than the control group $(P<0.05)$. The result also suggested that the medication in each treatment groups had weak effects on the growth of rats during only 2 weeks of repletion.

Table 4. The body weight changes of rats in each group $(\bar{X} \pm \mathbf{s}, \mathbf{n}=\mathbf{8})$

\begin{tabular}{|c|c|c|c|c|c|c|c|}
\hline \multirow{2}{*}{ groups } & \multicolumn{7}{|c|}{ Body weight(g) } \\
\hline & 0 week & 1 week & 2 weeks & 3 weeks & 4 weeks & 5 weeks & 6 weeks \\
\hline control & $80 \pm 5$ & $117 \pm 5$ & $154 \pm 6$ & $178 \pm 8$ & $202 \pm 10$ & $220 \pm 9$ & $242 \pm 9$ \\
\hline model & $79 \pm 6$ & $99 \pm 4^{*}$ & $127 \pm 7^{*}$ & $141 \pm 8^{*}$ & $162 \pm 7^{*}$ & $172 \pm 10^{*}$ & $191 \pm 9^{*}$ \\
\hline $\mathrm{FeSO}_{4}$ & $79 \pm 5$ & $99 \pm 5^{*}$ & $129 \pm 8^{*}$ & $145 \pm 8^{*}$ & $161 \pm 7^{*}$ & $177 \pm 7^{*}$ & $192 \pm 11^{*}$ \\
\hline Low-dose CSF & $79 \pm 4$ & $99 \pm 6^{*}$ & $126 \pm 8^{*}$ & $140 \pm 10^{*}$ & $158 \pm 12^{*}$ & $173 \pm 11^{*}$ & $191 \pm 12^{*}$ \\
\hline medium-dose CSF & $81 \pm 6$ & $101 \pm 6^{*}$ & $128 \pm 8^{*}$ & $143 \pm 9^{*}$ & $159 \pm 10^{*}$ & $173 \pm 11^{*}$ & $191 \pm 10^{*}$ \\
\hline high-dose CSF & $80 \pm 4$ & $100 \pm 5^{*}$ & $125 \pm 8^{*}$ & $139 \pm 9^{*}$ & $157 \pm 9^{*}$ & $170 \pm 9^{*}$ & $190 \pm 13^{*}$ \\
\hline
\end{tabular}

*Compared with control group, $P<0.05$

\section{Discussion}

Chickpea ranks third (FAO 2008) among food legumes for world production, one of important characteristics providing nutrition for human health as iron-containing complementary foods. The major objective of this study was to evaluate the effects of on IDA rats. Meanwhile, its effects of iron supplements on Wistarrat were also studied for the first time. It was worth noting that CSF can be used as an effective iron supplement as we expected.

Iron is necessary for hemoglobin synthesis, it is logical to assume that any iron inadequacy would be reflected in a slower hemoglobin synthetic rate [14]. Concentration of $\mathrm{Hb}$, is a key indicator to decide whether anemia has existed and measure iron Status [15]. In the present study, the Hbcontraction was investigated before and after the model built successfully. Fortunately, significant changes were detected in IDA rats when fed iron supplement, the levels of $\mathrm{Hb}$ in the $\mathrm{CSF}$ and $\mathrm{FeSO}_{4}$ groups were returned to the same level as those of the control group, meaning that CSF can be a potential iron supplements. A marked increase in hemoglobin observed in the rats fed the iron supplement diet can be explained by repletion of hemoglobin iron. Moreover, the parameters associated with blood counts, i.e. RBC and HCT were measured and showed that high-dose CSF group can achieve the higher levels than the control, which might also be explained by the increase in the content of iron in the diet with the CSF isolate. 
Serum iron is a medical laboratory test that measures how much circulating iron that is bound to transferrin. In this study, the IDA rats had lower serum iron than the control group, while the IDA rats supplemented with CSF and $\mathrm{FeSO}_{4}$ showed increased serum iron in almost parallel level, which is in line with as previous report [14], implying that CSF is a potential preferred iron supplement, and the affinity of transferrin for iron derived from ferritin is comparatively high.

The effects of iron from $\mathrm{CSF}$ and $\mathrm{FeSO}_{4}$ were also determined by measuring the ratio of tissue weights to body weight $(\mathrm{g} / \mathrm{kg})$ of the experimental rats (Table 3$)$. In this study, the response was directly related to the high amount of iron that could be delivered directly to these tissues. Rats with IDA have more requirements of iron in the liver and kidney, rather than heart and spleen. To some extent, it is than suggested than liver and kidney are the major storage sites for iron. In addition, it is also required to replenish iron during the period of IDA, as long-term of iron defiance will have negative impacts on the important function of viscera, especially immune function and antiinfection ability.

At the early stage of experiment, there were no noticeable differences in body weight gains between these dietary groups. Body weight gains pronouncedly decreased in iron-deficient groups after depletion, suggesting that iron is accepted as an important indicator for promoting rats' growth in comparison with the previous reportes $[16,17,18]$. Accordingly, rats in the ironrepletion groups such as $\mathrm{CSF}$ and $\mathrm{FeSO}_{4}$ groups did not show body weight growth and were far lower than the control group. At the same time, different doses of CSF did not provide any obvious clues that can fully explain the drug independence, probably due to the short duration of the experiment groups.

\section{Conclusion}

In summary, the improving effect of CSF on iron deficiency anemia was investigated in female Wistarrats induced by oral administration of iron-deficient diet. The factors, such as weights, hematological, serum iron, blood parameters, tissue Weight of anemic rats fed with CSF were explored. It demonstrated that CSF may possess a great potential to be used as iron supplement because it is effective in the promotion of iron absorption. Further study is also required to investigate the mechanism for the positive effects of CSF on the bioavailability of iron.

\section{Acknowledgments}

This research was financially supported by National Natural Science Foundation of China (Grant Nos. 81102889). The authors are grateful to all of the people who offered help in this study.

\section{List of Abbreviations}

\author{
CSF: Chickpea Seeds Ferritin \\ Hb: Hemoglobin \\ HCT: Hematocrit
}

IDA: Iron Deficiency Anemia

SI: Serum Iron

RBC: Red Blood Cell

\section{References}

[1] Haas, J.D. and Brownlie,T, "Iron deficiency and reduced work capacity: a critical review of the research to determine a causal relationship”. The Journal of nutrition, 131 (2): 676S-690S. 2001.

[2] Grantham-McGregor, S.andAni, C,"A review of studies on the effect of iron deficiency on cognitive development in children". The Journal of nutrition, 131 (2): 649S-668S. 2001.

[3] Sachdev, H.P.S. and Gera, T, "Nestel P "Effect of iron supplementation on mental and motor development in children: systematic review of randomised controlled trials". Public health nutrition, 8 (02): 117-132. 2005.

[4] Levy, A., Fraser, D., Katz, M., Mazor, M. andSheiner,E, "Maternal anemia during pregnancy is an independent risk factor for low birthweight and preterm delivery". European Journal of Obstetrics \& Gynecology and Reproductive Biology, 122 (2): 182186. 2005.

[5] Ahluwalia, N., Sun, J., Krause, D., Mastro, A. and Handte,G, "Immune function is impaired in iron-deficient, homebound, older women”. The American journal of clinical nutrition, 79 (3): 516521. 2004.

[6] Moench-Pfanner, R., de Pee S, Bloem, M.W., Foote, D.,Kosen, S. and Webb, P, "Food-for-work programs in Indonesia had a limited effect on anemia”. The Journal of nutrition, 135 (6): 1423-1429. 2005.

[7] Layrisse, M., García-Casal, M.N., Solano, L., Barón, M.A., Arguello, F., Llovera, D. andTropper, E, "Iron bioavailability in humans from breakfasts enriched with iron bis-glycine chelate, phytates and polyphenols". The Journal of nutrition, 130(9): 21952199. 2000.

[8] Layrisse, M., García-Casal, M.N., Solano, L, Barón, M.A., Arguello, F, Llovera, D. and Tropper, E, "Milk inhibits and ascorbic acid favors ferrous bis-glycine chelate bioavailability in humans". The Journal of nutrition, 127 (7): 1407-1411. 2000.

[9] Pineda, O., Wayne Ashmead, H.D., Perez, J.M. and Lemus, C.P, "Effectiveness of iron amino acid chelate on the treatment of iron deficiency anemia in adolescents”. Journal of Applied Nutrition 46 (1): 2-13. 1994

[10] Pizarro, F., Olivares, M., Hertrampf, E., Mazariegos, D.I., Arredondo, M., Letelier, A. andGidi, V, "Iron bis-glycine chelate competes for the nonheme-iron absorption pathway". The American journal of clinical nutrition, 76 (3): 577-581. 2002.

[11] Kumar, G.B.S., Srinivas, L. and Ganapathi, T.R, "Iron fortification of banana by the expression of soybean ferritin". Biological trace element research, 142 (2): 232-241. 2011.

[12] Tuma, R.B., Yuyama, L.K.O., Aguiar, J.P.L. and Marques, H.O, "Impacto da farinha de mandiocafortificada com ferroaminoácidoquelato no nível de hemoglobina de préescolares”. Rev. nutr, 16 (1): 29-39. 2003.

[13] Yun, S., Zhang, T., Li, M., Chen, B. and Zhao, G, "Proanthocyanidins inhibit iron absorption from soybean (Glycine max) seed ferritin in rats with iron deficiency anemia”. Plant foods for human nutrition, 66 (3): 212-217.2011.

[14] Wang, F.R., Xie, Z. G., Ye, X.Q., Deng, S.G., Hu, Y.Q., Guo, X. and Chen, S.G, "Effectiveness of treatment of iron deficiency anemia in rats with squid ink melanin-Fe". Food \& function, 5(1):123-128.2014.

[15] Damodar, S., Raghunath, S.T., Murthy, S., Jayanthi, K.J. and Latha, B.S, "Low Hemoglobin Density as a Measure of Iron Status”. Indian Journal of Hematology and Blood Transfusio, 29 (2): 75-76. 2013.

[16] Borel, M.J., Smith, S.H., Brigham, D.E. and Beard, J.L, "The impact of varying degrees of iron nutriture on several functional consequences of iron deficiency in rats”. The Journal of nutrition, 121 (5): 729-736. 1991.

[17] Strube, Y.N.J., Beard, J.L. and Ross, A.C, "Iron deficiency and marginal vitamin A deficiency affect growth, hematological indices and the regulation of iron metabolism genes in rats". The Journal of nutrition, 132 (12): 3607-3615.2002.

[18] Rossi, M.A., Carillo, S.V. and Oliveira, J.S.M, "The effect of iron deficiency anemia in the rat on catecholamine levels and heart morphology”. Cardiovascular research, 15 (6): 313-319. 1981. 